\title{
The Determinants of Strategic Information System Planning (SISP) Success: A Proposed Framework for Small and Medium-Sized Enterprises (SMEs)
}

\author{
Raja Haslinda Raja Mohd. Ali ${ }^{1}$, Rosli Mohamad ${ }^{1}$ and Alexei Tretiakov ${ }^{2}$ \\ ${ }^{1}$ School of Accountancy, College of Business, Universiti Utara Malaysia, Kedah, Malaysia \\ ${ }^{2}$ Department of Management, College of Business, Massey University, New Zealand
}

Correspondence should be addressed to: Raja Haslinda Raja Mohd. Ali; rj.linda@uum.edu.my

Received 12 January 2013; Accepted 29 August 2013; Published 30 October 2013

Academic Editor: Jaroslav Jandos

Copyright (C) 2013 Raja Haslinda Raja Mohd. Ali, Rosli Mohamad and Alexei Tretiakov. Distributed under Creative Commons CC-BY 3.0

\begin{abstract}
The growing importance of Information System (IS) to support business operation demands for adequate IS planning. Good IS planning enables organizations to closely align the IS and strategic business objectives. Such alignment ultimately ensures organizations to gain competitive advantages from IS-related investment. Despite extensive works to understand SISP practices in large organizations, works are still limited in the context of Small and Medium Enterprise (SMEs). This issue is worth further investigation in view of the increasing importance of IS to support many facets of the SMEs operation. More importantly, due to inherent resource constraints among SMEs to invest in IS, top management commitment as well as user participation in IS planning activities are getting more crucial. This study, therefore proposes a framework to assess the effect of top management commitment and user participation on SISP success. The findings are of relevance for firm's top management in ensuring SISP success.
\end{abstract}

Keywords: Top Management Commitment, User Participation, Strategic Information System Planning, SMEs.

\section{Introduction}

The dependency of business on Information Systems (IS) in daily operations suggests that the organizations need to pay more attention to the IS planning which aims to facilitate the achievement of the organization's business goals (Basu et al., 2002). Despite substantial growth of studies amongst large firms, IS practices among the smaller firms have received somewhat limited attention in previous works (Powell \& Woerndl, 2008). This clearly contradicts the fact that the SMEs form a major component of established business in most countries. With SMEs dominating more than $90 \%$ of the total registered businesses; the sector contributes quite substantially to the country's gross 
domestic products and employment opportunities (WASME, 2006). In fact, SMEs are facing greater threats compared to larger firms because of the constant changes in the business environment. Consequently, the SMEs are now getting more dependent over the IS to enhance their business effectiveness (Schubert \& Leimstoll, 2007).

Regardless of growing interest over its potentials, SMEs face constant challenges to embrace IS effectively. Some firms are struggling to optimize IS values as they are giving low priority on technologically related investment (Fuller, 1996). This is likely because firms hardly employ IS strategically (Schubert \& Leimstoll, 2007). The SMEs mainly considers IS to support firms' administrative functions such as accounting, inventory management and finance (Temtime et al., 2003). Several studies have also revealed that not all firms are successful in deploying IS due to lack of significant knowledge and capability to plan and manage IS-related projects (Ong \& Lin, 2011). In some other cases, firms fail to align various IS solutions with their business strategy and the corresponding business functions (Cragg \& Mills, 2011).

Although various areas of studies in IS planning have been conducted in large organizations, very limited studies considered the small and medium-sized organizations. Considering the emerging importance of IS in one hand, and firm challenges to embrace IS effectively on the other, it is incumbent to understand what makes successful SISP in the context of the SMEs sector. On top of that, the SISP frameworks available for larger firms may not perfectly reflect the same phenomena in SMEs (Premkumar, 2003). The SMEs are well known for their resource poverty with respect to financial as well as IS technical expertise (Thong, 2001). With restricted resources available, IS planning becomes even more crucial for the firms.

In view of limited empirical studies available, this study is proposed to examine the effect of top management commitment and user participation on SISP success amongst the SMEs. This paper is organized as follows. The next section provides detailed discussions on the theoretical perspective of SISP, nature of SMEs and their IS practices. The third section elaborates further on the method of conducting the study. Authors reserves the last section for the conclusion of the proposed study.

\section{Literature Review}

\section{Strategic Information System Planning}

SISP is a process of identifying an organization's portfolio of computer-based applications and technologies that could help the organizations in executing their business plans and achieving their business objectives (Lederer \& Salmela, 1996). Whilst SISP concerns more on the future and how IS could help the organization to achieve the organization's business objectives and mission, operational IS planning concerns more on the day-to-day implementation of strategic planning. Therefore, in this study we will focus only on the strategic IS planning.

The importance of SISP has been highlighted in a number of studies (Bechor et al., 2010; Pun \& Lee, 2000; Spremic \& Strugar, 2002). SISP assists the organization with the identification of databases and systems to support them and helps the organization select applications for current and future needs (Carlson, 1979) and discover new applications with the potential to create an advantage over competitors (Boynton \& Zmud, 1987; Ives \& Learmonth, 1984; Porter \& Miller, 1985).

The theory of SISP was initially discussed by Lederer and Salmela (1996) through their input-process-output model. Their model provides seven constructs which include the environmental factors, both internal and external, and the organization's resources as the main input factor of SISP process. The immediate output of the planning process is the SISP. The plan was then being implemented with the ultimate outcome being a better alignment between the internal environment (including the IS and the IT 
infrastructure) and the organization's strategic goals.

The organization's resources usually include the formation of a project team and identification of a team leader. The team then carries out an extended study to identify any computer-based applications that could help the organization to achieve its business goals (Lederer \& Sethi, 1988). Bechor et al. (2010) suggested that the extended study carried out by project teams should identify the most suitable IS, information technology activities, and policies in the long-term. Extended studies carried out by project teams include the identification of the organization's strengths and weaknesses, the internal environment (including the organization's resources) and the external environment. This shows that information provided by the users and top management is very crucial in the SISP process with higher commitment and participation resulting in better flow of information.

The role of participation and commitment by employees at different levels was highlighted in a number of studies. Earl (1993) found that management participation, IS-user relationships, user awareness and education, and management ownership and practice of SISP influence the planning process. Smits et al. (1997) found that information strategy (the outcome of the planning process) is influenced by the participation and commitment of senior management, users, and the IS team. A survey study of 199 large USA firms conducted by Basu et al. (2002) concluded that stakeholder commitment (organizational, senior management and team involvement) influences the SISP process.

Although extensive works have been carried out to examine SISP as practiced by large organizations, there have been scarce studies that investigate the applicability of SISP amongst the SMEs. With limited numbers of employees and less complicated business structure, the top management commitment and users involvement could play more substantial roles in SISP activities. In response, the next section describes SMEs characteristics and there IS practices.

\section{SMEs and IS Practices}

In most nations, SMEs have a relatively dominant presence in relative to larger firms. In the context of Malaysia, the SMEs account for more than $99 \%$ of the established businesses (NDSC, 2011). Regardless of their substantial presence, the SME sector moderately contributes to the national's productivity. Cumulatively the sector contributes around $40 \%$ of the nation's gross domestic products (GDP) and provides about $57 \%$ of national employment opportunities (NSDC, 2011). Nevertheless, the present achievement is reported as somewhat lower in relative to other neighbouring countries such as Singapore, Japan, Korea, and China that contribute between $50 \%$ and $60 \%$ to their respective economy (Mohd Aris, 2007).

Considering the fact that the sector is the backbone of the nation's growth, the government is constantly finding ways to extend productivity of the SMEs. Such commitment is reflected in the government mapping of various national agendas such as the Industrial Manufacturing Plan 3 (IMP3), the Tenth Malaysia Plan (10MP) and Government Transformation Plan (GTP). The government further established ministries and agencies focusing solely on SMEs development programs. Consistent with the globalization challenges, the Ninth Malaysia Plan (9MP: 2006 - 2010) promoted IT utilization as a possible mean to strengthen firm's operations across the business value chain. The role of IT for productivity enhancement remains salient as more initiatives have been proposed in formulating the $10^{\text {th }}$ Malaysia Plan. Overall, the $10^{\text {th }}$ Malaysia Plan strives hard to gear up the SME sector to be the national engine of growth and innovation (Economic Planning Unit [EPU], 2010).

Apart from the firm's size, SMEs can be distinguished from their larger counterparts in the aspects of management and planning, availability of resources, market scope, and risk exposure (Macgregor \& Vrazalic, 2006). Therefore, 
the unique nature of the SME sector might have different implications in their business operation and how the firms respond to the changes in their business environment. Consequently, these characteristics, to some extent influence how firms manage IS in their business.

Deployment of appropriate IS has been well accepted as one of the possible tools to extend SMEs productivity (Kotelnikov, 2007). Therefore, IS has made remarkable presence in various kinds of businesses as it is viewed as a useful tool to enhance business efficiency. Ideally, IS would facilitate firms to manage administrative tasks, enhance production activities, and expand product/service market (WASME, 2006). Extensive deployment of IS further facilitates firms to compete with larger organizations (Dibrell et al., 2008).

Nevertheless, IS deployment is not well received by the SMEs. Most firms keep their traditional ways of operating their businesses. Slow development of IS deployment among SMEs has been attributed to various barriers, particularly the top management support, limited knowledge or relevant skills (Lip-Sam, 2006), inadequate IT infrastructure and technical supports (Kurnia et al., 2009) as well as security and trust issues (Narayanasamy et al. 2008). Moreover, lack of financial resources further restricts firms to invest extensively on IS related projects (Yrle, Hartman \& Walsh, 2004). In another respect, the inadequate presence of in-house IT experts even put greater pressure for the firms to outsource most of their IS-related projects and have greater reliance on other external parties (Levy, Powell \& Galliers, 1999). Owing to various constraints highlighted, firms hardly realized the strategic values of IS.

Following overwhelming claims of IS potentials on one hand, and the challenges that firms are facing on the other; SME sector has been the subject of many studies over the years. Previous works have concentrated on several issues of IS practices. Investigations to understand the drivers/inhibitors of IS adoption substantially dominate the previous studies (Premkumar, 2003). The studies mainly explore drivers or inhibitors of IS adoption among the firms.

However, the cost of deploying IS related solution has gotten cheaper nowadays which makes it more affordable for the SMEs. Consequently, IS has penetrated into wider aspects of firm's operation. Bharati and Chaudhury (2006) revealed that IS deployment has expanded into various aspects of the value chain. The roles of IS are getting more paramount to support secondary value chain activities and even extended beyond firm's operation (Schubert \& Leimstoll, 2007). In response to extensive IS deployment among firms, considerable efforts have been initiated to examine the intensity of IS deployment across business operation (Ashrafi \& Murtaza, 2008) and the firms' level of IS sophistication (Kutlu \& Ozturan, 2008). Other works had also tried to reveal factors that distinguish firms that are successful in IS deployment initiative than firms that are not (Thong, 2001).

In view of expanding IS capabilities within firm's operation, adequate IS planning is necessary to ensure its effectiveness in support of business strategic objectives. Needless to say, limited works have been reported on assessing strategic IS issues amongst SMEs. To illustrate, Levy, Powell and Galliers (1999) proposed a revised Information System Strategies (ISS) to reflect SMEs nature of the operation. In another study, Levy \& Powell (2003) reported that lack of strategic alignment explains SMEs failure to benefit from IS investment. In a similar vein, other studies indicated that strategic alignment leads to greater IS success and firm performance (Cragg et al., 2002; Garg \& Goyal, 2012; Hussin \& Adam, 2011). More importantly, adequate IS planning would facilitate firms to realize the strategic roles of IS in their operation. IS planning effectiveness might be enhanced by taking into consideration users' needs as well as their involvement in IS planning (Raymond, Croteau \& Bergeron, 2011). Finally, SISP study focusing on SMEs context is greatly needed to establish further understanding of SISP success from industry level perspective. Industry level 
strategies such as SME sector constantly change over time which therefore demands for investigation at industrial level perspective (Gable, 2010).

\section{Research Framework and Hypotheses Development}

Responding to the research objectives highlighted and literature review discussion, this paper proposes to examine the effect of top management commitment and user participation on SISP success from SME perspective. It is hypothesized that higher levels of user participation and higher levels of top management commitment resulted in higher levels of SISP success.

\section{Top Management Commitment and SISP Success}

Top management commitment refers to top management awareness of, involvement in, and proactive advancement of SISP. Top management commitment affects SISP success because this level of management provides information about the organization's strategic goals to the SISP process. Moreover, top management may be allocated to the planning process as a resource.

In the larger firm context, many firms have reported the significant importance of top management commitment. For example, Premkumar \& King (1994) have found that the resources (including top management commitment) affected SISP success. Basu et al. (2002) also found that senior management involvement affected the SISP success. Chi et al. (2005), in a study of USbased organizations reported that top management affected environmental assessment, and environmental assessment affected the SISP success. Considering its size, top management of the SMEs tends to have substantial roles in most aspects of the firm decision (Thong, 2001). Therefore, they tend to have a stronger influence on SISP success. Based on this argument, this study asserts that:
H1: Higher levels of top management commitment leads to better SISP success.

\section{User Participation and IS Planning Success}

Apart from top management commitment, the role of user participation has been considered as one of the factors to affect SISP success. User participation refers to the extent of involvement of regular employees (current or potential users of IS) in the SISP process. User participation affects SISP success because users provide information about the internal and external environment in the SISP process, and because users are allocated as resources to the planning process.

Premkumar and King (1994), studies of organizations in the USA found that resources (a construct that included items relating to user participation) affected SISP success. In a similar vein, Newkirk and Lederer (2007) found that personnel resource planning (a construct that included items relating to user participation) affected SISP success. Sridhar et al. (2009), in a simulation study with MBA students, found that user participation affected the quality of the SISP process. A number of researchers have also suggested that higher levels of user participation may lead to better success in system implementation. McKeen and Guimaraes (1997) found that user participation affected user satisfaction in all stages of systems development. Lu and Wang (1997) study of Taiwan organizations reported that user participation affected the system's success at all three stages of MIS growth, defined as initiation, development, and maturity.

In SMEs context, Thong (2001) further contends that active user involvement in any IS planning activity nurtures 'sense of ownership' among the users as the IS being developed in accordance with their requirements. Therefore, it is interesting to examine whether, the same prediction applies in SMEs environment. This argument leads to the second hypothesis: 
H2: Higher levels of user participation leads to better SISP success.

\section{Research Method}

The study is intended to focus on Malaysian SMEs. National SMEs Development Council's (2005) classifies firms as micro, small or medium-sized based on the number of employees (FTEs) and annual sales turnover, depending on the different nature of the firm's operation. As for the manufacturing sector, small firm refers to business with FTEs of between 5 and 50 . Meanwhile, business with FTEs from 50 to 150 is classified as medium-sized firm. This study, however, excludes micro business based on the justification that; (i) majority of the micro firms have limited capabilities to employ IT/IS applications due to cost factors (Macgregor \& Vrazalic, 2006) and (ii) unique nature of operation as compared to larger businesses (Schubert \& Leimstoll, 2007).

With respect to sector, this study focuses on manufacturing-based firms. This sector is more likely to have a greater level of IT maturity, in terms of IT deployment and IS management (Cragg et al., 2002). In view of various directories of SMEs available, this study, therefore, considers manufacturing company directory (Federation of Malaysian Manufacturers [FMM], 2012) as a sampling frame. The directory provides the most up to date information of Malaysian manufacturers as FMM publishes its member profiles on an annual basis. Although the directory contains more than 2,500 registered members, only 1,565 firms (which are classified either as small and medium-sized firms) are considered appropriate as the samples.

The unit of analysis for this study is an individual organization. The targeted respondent is the IS manager or other member of the top management. He or she generally has extensive knowledge of IS of the firm, access to an organization's data, and greater capability to complete the questionnaire (Basu et al., 2002). Apart from that, senior managers generally have direct involvement in most of the firm's IS related development as SMEs usually have unclear organizational structure for decision making purpose (Levy, Powell \& Galliers, 1999). Thus, the firms rarely have specific department that handles IS-related matters.

This study will employ mail survey technique approach in collecting empirical evidences from the sample firms. A selfadministered postal questionnaire will be mailed to the respective firm. The questionnaire comprises of three major sections. The first section gathers information about the organization's experience (in years) in SISP and the percentage of outsourcing the SISP development (if any). The second section assesses firm's SISP success and its determinants (top management commitment and user participation). The SISP success is measured by 10 items using 5-point Likert Scale from "Not at all" to "To a very great extent" adapted from Lederer and Sethi (1996). Top management commitment is measured by seven items with the same scale as SISP success which were adapted from Basu et.al (2002), whilst user participation construct is measured by five items using 5-point Likert scale from "Strongly disagree" to "Strongly agree" as adapted from Papke-Shields, Malhotra and Grover (2002). The last section seeks demographic data on participating organizations and on the respondents.

\section{Conclusion}

IS planning facilitates firms to identify potential IS or technological applications that could be useful to extend the organization's efficiency as well as to achieve firm's desired objectives. However, earlier literature concentrates heavily on understanding IS planning practice among large organizations with very limited focus given on the SMEs. Due to the substantial hardware cost reduction, IS could be more affordable for smaller firms. In view of the substantial dominance of the SMEs in most developing economies and an increasing importance of IS utilization by SMEs, SISP becomes more crucial to facilitate more effective IS implementation. Hence, this paper proposes a study to investigate SISP 
as practiced amongst the SMEs. The specific focus of the study is to examine the effect of top management commitment and users participation in IS planning activities in ensuring SISP success in SMEs. Upon completing the empirical data collection, this study is expected to offer a model that assesses the effect of user participation and top management commitment to strategic IS planning success of the firms. The findings are of relevance for firm's top management in developing more efficient and effective strategic IS planning.

\section{Acknowledgement}

The authors would like to thank the management of Universiti Utara Malaysia for funding this research project via Leadership Development Program Scheme (LEADS).

\section{References}

Ashrafi, R. \& Murtaza, M. (2008). "Usages and Effects of Information and Communication Technologies on Small and Medium Sized Enterprises in Oman," Retrieved from http://aisel.aisnet.org/confirm2008/60

Basu, V., Hartono, E., Lederer, A. L. \& Sethi, V. (2002). "The Impact of Organisational Commitment, Senior Management Involvement, and Team Involvement on Strategic Information Systems Planning," Information \& Management, 39, 513-524.

Bechor, T., Neumann, S., Zviran, M. \& Glezer, C. (2010). "A Contingency Model for Estimating Success of Strategic Information Systems Planning," Information \& Management, 47(1), 17-29.

Bharati, P. \& Chaudhury, A. (2006). "Studying the Current Status of Technology Adoption," Communications of the ACM, 49(10), 88 - 93.

Boynton, A. C. \& Zmud, R. W. (1987). "Information Technology Planning in the 1990's: Directions for Practice and Research," MIS Quarterly, 11(1), 59-71.
Carlson, W. M. (1979). "Business Information Analysis and Integration Technique (BIAIT): The New Horizon," SIGMIS Database, 10(4), 3-9.

Chi, L., Jones, K. G., Lederer, A. L., Li, P., Newkirk, H. E. \& Sethi, V. (2005). "Environmental Assessment in Strategic Information Systems Planning," International Journal of Information Management, 25(3), 253-269.

Cragg, P., King, M. \& Hussin, H. (2002). "IT Alignment and Firm Performance in Small Manufacturing Firms," Journal of Strategic Information Systems, 11, 109-132.

Cragg, P. \& Mills, A. (2011). "IT Support for Business Process in SMEs," Business Process Management Journal. 17 (5), 697 - 710.

Dibrell, C., Davis, P. S. \& Craig, J. (2008). "Fueling Innovation through Information Technology in SMEs," Journal of Small Business Management, 46: 203-218.

Earl, M. J. (1993). "Experiences in Strategic Information Systems Planning," MIS Quarterly, 1-24.

Economic Planning Unit [EPU]. (2010). 'Tenth Malaysia Plan: 2011 - 2015,' Putrajaya, Malaysia: The Economic Planning Unit, Prime Minister's Department.

Federation of Malaysian Manufacturer [FMM]. (2012). "FMM Directory of Malaysian Industries 2012 (43rd Edition)," Kuala Lumpur, Malaysia: Federation of Malaysian Manufacturer.

Fuller, T. (1996). "Fulfilling IT Needs in Small Businesses: A Recursive Learning Model," International Small Business Journal, 14 (4), 25 - 45.

Gable, G. (2010). "Strategic Information Systems Research: An Archival Analysis," The Journal of Strategic Information Systems, 19(1). Pp. 3-16. 
Garg, A. \& Goyal, D. P. (2012). "Striving towards Strategic Alignment in SMEs: An Empirical Analysis," Journal of Advances in Management Research, 9 (1), 77 - 95.

Hussin, H. \& Suhaimi, M. A. (2011). Information Technology and Business Alignment in Malaysian SMEs, IIUM Press: Selangor, Malaysia.

Ives, B. \& Learmonth, G. P. (1984). "The Information System as a Competitive Weapon," Communications of the ACM 27(12), 1193-1201.

Kotelnikov, V. (2007). 'Small and Medium Enterprises and ICT. Bangkok,' Thailand: UNDP Asia-Pacific Development Information Programme. Retrieved from http://www.apdip.net/news/sme.

Kurnia, S., Alzougool, B., Ali, M. \& Alhashmi, S. M. (2009). "Adoption of Electronic Commerce Technologies by SMEs in Malaysia," The 42nd Hawaii International Conference on Systems Science. Hawaii, USA.

Kutlu, B. \& Ozturan, M. (2008). "The Usage and Adoption of It among SMEs in Turkey: An Exploratory and Longitudinal Study," Journal of Information Technology Management, XIX(1), 12 - 24. Retrieved from http://jitm.ubalt.edu.

Lederer, A. L. \& Salmela, H. (1996). "Toward a Theory of Strategic Information Systems Planning," Journal of Strategic Information Systems, 237-253.

Lederer, A. L. \& Sethi, V. (1988). "The Implementation of Strategic Information Systems Planning Methodologies," MIS Quarterly, 12(3), 445-461.

Levy, M. \& Powell, P. (2003). "Exploring SME Internet Adoption: Towards a Contingent Model," Electronic Markets, 13(2), 173-181.

Levy, M., Powell, P. \& Galliers, R. (1999). "Assessing Information Systems Strategy Development Frameworks in SMEs," Information \& Management, 36, 247 - 261.
Lu, H. P. \& Wang, J. Y. (1997). "The Relationship between Management Styles, User Participation, and System Success Over MIS Growth Stages," Information and Management, 32, 203-213.

MacGregor, R. C. \& Vrazalic, L. (2006). "ECommerce Adoption Barriers in Small Businesses and the Differential Effects of Gender," Journal of Electronic Commerce in Organizations, 4(2), 1 - 24.

Mckeen, J. D. \& Guimaraes, T. (1997). "Successful Strategies for User Participation in Systems Development," Journal of Management Information Systems, 14(2), 133-150.

Mohd. Aris, N. (2007). "SMEs: Building Blocks for Economic Growth1," Department of Statistic: Kuala Lumpur, Malaysia.

Narayanasamy, K., Santhapparaj, A. S. \& Eze, U. C. (2008). 'An Empirical Study of Website Adoption among Small and Medium Enterprises (SMEs) in Malaysia,' Communications of the IBIMA, 2, 50 - 62 . Retrieved from http://www.ibimapublishing.com

National SMEs Development Council [NSDC]. (2005). "Definitions for Small and Medium Enterprises in Malaysia," Kuala Lumpur, Malaysia: National SMES Development Council.

National SME Development Council [NSDC]. (2011). 'SME Annual Report 2010/2011,' Kuala Lumpur, Malaysia: NSDC

Newkirk, H. E. \& Lederer, A. L. (2007). 'The Effectiveness of Strategic Information Systems Planning for Technical Resources, Personnel Resources, and Data Security in Environments of Heterogeneity and Hostility,' The Journal of Computer Information Systems, 34-44.

Ong, C. S. \& Lin, C. T. (2011). “Creating EBusiness Value and Firm Performance from Supply Chain Perspective," 15th Pacific Asia Conference on Information Systems (PACIS) 2011 (Pp. 1 - 14). Brisbane, Australia: Association for Information Systems. 
Papke-Shields, K. E., Malhotra, M. K. \& Grover, V. (2002). "Strategic Manufacturing Planning Systems and Their Linkage to Planning System Success," Decision Sciences, 33(1), 1-30.

Porter, M. E. \& Miller, V. E. (1985). "How Information Gives You Competitive Advantage," Harvard Business Review, 63(4).

Powell, P. \& Woerndl, M. (2008). "Time to Stop Searching the Important Things?," European Journal of Information Systems, $17,174-178$.

Premkumar, G. (2003). "A Meta-Analysis of Research on Information Technology Implementation in Small Business," Journal of Organizational Computing and Electronic Commerce, 13(2), 91 - 121.

Premkumar, G. \& King, W. R. (1994). "Organizational Characteristics and Information Systems Planning: An Empirical Study," Information Systems Research, 5(2), 75-109.

Pun, K. F. \& Lee, M. K. O. (2000). "A Proposed Management Model for the Development of Strategic Information Systems," International Journal of Technology Management, 20(3-4), 304-325.

Raymond, L., Croteau, A. M. \& Bergeron, F. (2011). "The Strategic Role of IT: An Empirical Study of Its Impact on IT Performance in Manufacturing SMEs," Paper Presented at ICIW 2011: The Sixth International Conference on Internet and Web Applications and Services, Netherland, 20 - 25 March 2011.

Schubert, P. \& Leimstoll, U. (2007). "Importance and Use of Information Technology in Small and Medium-Sized Companies," Electronic Markets, 17(1), 38 55.

Smits, M. T., Poel, K. G. V. D. \& Ribbers, P. M. A. (1997). "Assessment of Information Strategies in Insurance Companies in the Netherlands," Journal of Strategic Information Systems, 6, 129-148.
Spremic, M. \& Strugar, I. (2002). "Strategic IS Planning Practise in Croatia Organizational and Managerial Challenges," Internation Journal of Accounting Information Systems, 3, 183-200.

Sridhar, V., Nath, D. \& Malik, A. (2009). "Analysis of User Involvement and Participation on the Quality of IS Planning Projects: An Exploratory Study," Journal of Organisational and End User Computing, 21(3).

Temtime, Z. T., Chinyoka, S. V. \& Shunda, J. P. W. (2003). "Toward Strategic Use of IT in SMEs: A Developing Country Perspective," Information Management \& Computer Security, 11 (5), 230 - 237.

Thi, L. S. (2006). "Electronic Commerce Adoption among Manufacturing SMEs in Malaysia," (Unpublished Doctoral Dissertation). University of Laubourough, Loughborough, United Kingdom.

Thong, J. Y. L. (2001). "Resource Constraints and Information Systems Implementation in Singaporean Small Businesses," Omega, 29(2), 143-156.

World Association for SMEs [WASME] (2006). 'Annual Report for 2004 - 2006,' WASME: Uttar Pradesh, India. Retrieved from http://www.wasmeinfo.org

Yrle, A. C., Hartman, S. J. \& Walsh, K. R. (2004). "E-Business: Linking Available Services and Entrepreneurs' Needs," Journal of Small Business and Enterprise Development, 11(3), 390. 